\title{
p.Val452Ile mutation of the SLC25A13 gene in a Turkish patient with citrin deficiency
}

\author{
Berna Şeker-Yılmaz , Deniz Kör², Gökhan Tümgör ${ }^{3}$, Serdar Ceylaner ${ }^{4}$, Neslihan Önenli- \\ Mungan² \\ ${ }^{1}$ Division of Pediatric Metabolism, Department of Pediatrics, Mersin City Hospital, Mersin; Divisions of ${ }^{2}$ Pediatric Metabolism, \\ ${ }^{3}$ Pediatric Gastroenterology, Department of Pediatrics Çukurova University Faculty of Medicine Adana; ${ }^{4}$ Intergen Genetics \\ Laboratory, Medical Genetics, Ankara, Turkey.E-mail: berna_seker@yahoo.co.uk \\ Received: 7th December 2016, Revised: 5th February 2017, Accepted: 6th February 2017
}

SUMMARY: Şeker-Yılmaz B, Kör D, Tümgör G, Ceylaner S, Önenli-Mungan N. p.Val452Ile mutation of the SLC25A13 gene in a Turkish patient with citrin deficiency. Turk J Pediatr 2017; 59: 311-314.

Citrin deficiency is an autosomal recessive metabolic disorder, which is caused by pathogenic mutations in the SLC25A13 gene on chromosome $7 \mathrm{q} 21.3$, as the causative gene that encodes the liver type aspartate/glutamate carrier isoform 2 (AGC2). One of the main clinical presentations is neonatal intrahepatic cholestatic hepatitis caused by citrin deficiency.

We report a Turkish child presented with prolonged neonatal jaundice associated with elevated plasma citrulline and galactosuria. NICCD was suspected at this point and mutation study of SLC25A13 showed that she was homozygous for the missense NM_014251.2:c.1354G>A (NP_055066.1:p. Val452Ile) (dbSNP: rs143877538) mutation. Dramatic response was observed to the dietary treatment with medium-chain triglycerides containing formula, ursodeoxycholic acid and fat-soluble vitamin supplementation.

The minor allele frequency of this variant was given as nearly as 0.01 in the South Asian population; it seems like a disease causing variant. This is the first report of this variant in the Turkish and European population.

Key words: citrin deficiency, prolonged neonatal jaundice, novel mutation.

Citrin deficiency, caused by mutations in the SLC25A13 gene on chromosome 7q21.3, is an autosomal recessive disease that was first discovered in Japan and thereafter identified worldwide ${ }^{1}$. Deficiency of citrin, which is the liver-specific isoform of the mitochondrial aspartate/glutamate carrier (AGC2), has three major age dependent clinical phenotypes: Neonatal Intrahepatic Cholestasis caused by Citrin Deficiency (NICCD, OMIM\#605814) in infants, adult-onset citrullinemia type II (CTLN2, OMIM\#603471) in adolescents and adults, and Failure to Thrive and Dyslipidemia caused by Citrin Deficiency (FTTDCD) in between these age groups ${ }^{2}$. NICCD patients present in the first few months of life with milder symptoms characterized by intrahepatic cholestasis, diffuse fatty liver, parenchymal cellular infiltration associated with hepatic fibrosis, hypoalbuminemia, coagulopathy, liver dysfunction with or without hypoglycemia, galactosuria, and increased $\alpha$-fetoprotein, multiple aminoacidemia including elevated citrulline, arginine, threonine, methionine, phenylalanine, and tyrosine concentrations and threonine/serine ratio ${ }^{3}$. In this report we describe a new Turkish case of NICCD with a SLC25A13 mutation which is very frequent in South Asian population like a polymorphism to emphasize its probable disease causing nature and the effectiveness of the treatment.

\section{Case Report}

A three-month-old boy of consanguineous Turkish parents was referred to our clinic due to prolonged neonatal jaundice. There was no family history. After an uneventful antenatal and perinatal period at the 3rd day of life he presented with neonatal jaundice and received phototherapy. At the initial 
administration icterus with pale colored stools, failure to thrive and mild hepatomegaly were detected. Developmental milestones were normal and he had no dysmorphic features. The rest of the physical examination findings were unremarkable. Hepatic sonography showed features of fatty liver but normal biliary tract. Laboratory examination revealed hyperbilirubinemia (total bilirubin $6.3 \mathrm{mg} /$ $\mathrm{dl}$, conjugated bilirubin $2.7 \mathrm{mg} / \mathrm{dl}$ ). Liver transaminases were mildly elevated and serum gamma glutamyl transferase was normal (serum alanine aminotransferase $125 \mathrm{IU} / \mathrm{L}$ (control range 11-45 IU/L), serum aspartate aminotransferase $171 \mathrm{IU} / \mathrm{L}$ (control range 22-63 IU/L) and serum gamma glutamyl transferase 89 (control range 8-90 IU/L)). High AST/ ALT ratio was remarkable. He had no coagulopathy or hypoglycemia. His serum $\alpha$-fetoprotein $(\alpha \mathrm{FP})$ level was markedly elevated (41420 ng/ $\mathrm{ml}$ control range: $8.5 \pm 5.5$ ). Thyroid hormone profile, serum alpha-1 antitrypsin levels and glucose-6-phosphatase dehydrogenase screening were normal. Infectious causes of hepatitis were excluded. Although massive galactosuria was detected in metabolic urinary screening, galactose-1-phosphate uridyl transferase assay was normal. Ammonia levels were mildly elevated $38 \mu \mathrm{mol} / \mathrm{L}$ (N:11-35). Plasma amino acids analysis showed moderately elevated plasma citrulline and threonine and mildly elevated tyrosine. Increased threonine/serine ratio was detected. Normal urinary succinylacetone levels ruled out tyrosinemia. Serum bile

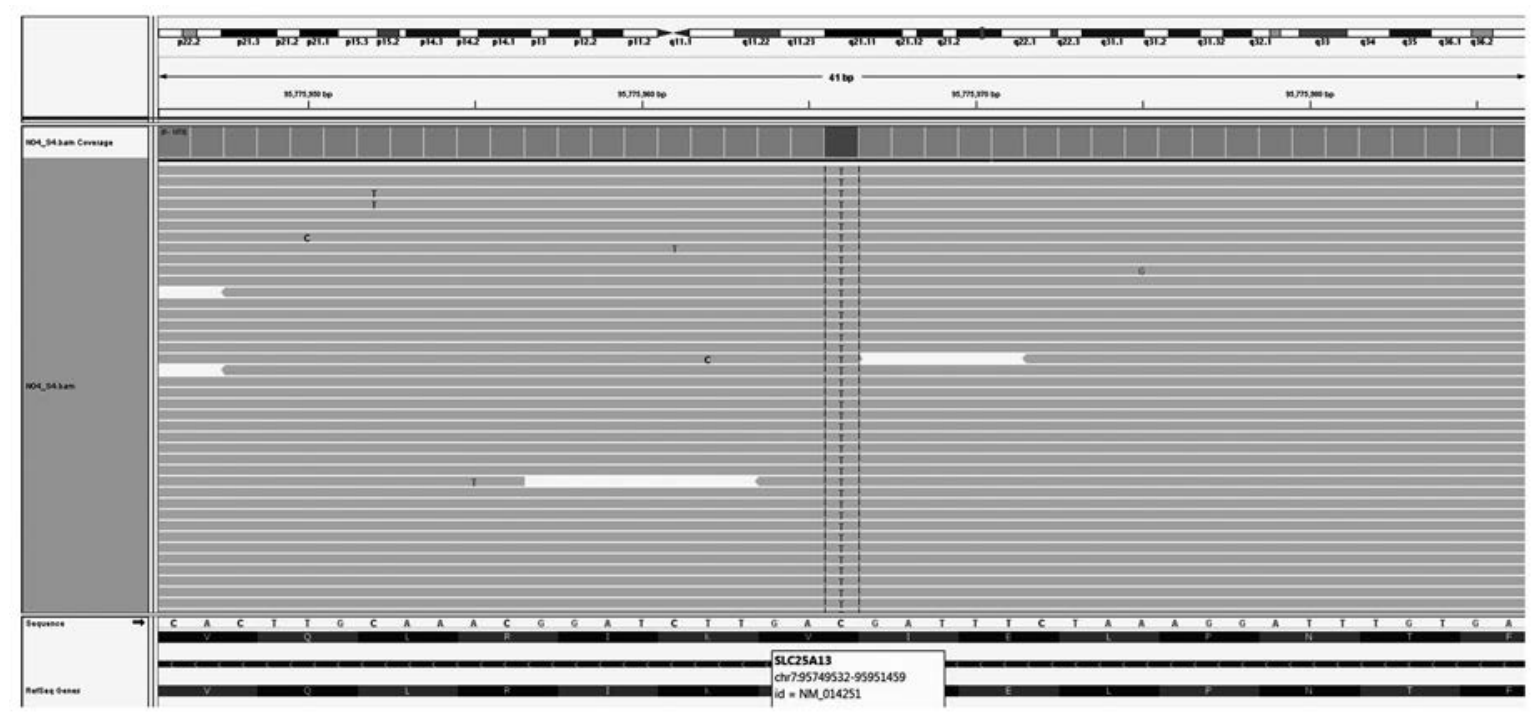

Fig. 1. Next generation sequencing of the SLC25A13 gene revealed homozygous p.Val452Ilemutation

Table I. The Course of Laboratory Data of the Patient from Diagnosis to the Last Visit.

\begin{tabular}{lllllll}
\hline & At diagnosis & 1 month & 3 month & 6 months & 12 months & 18 months \\
\hline $\begin{array}{c}\text { Total/conjugated bilirubin } \\
(<1 \mathrm{mg} / \mathrm{dl})\end{array}$ & $6.3 / 2.79$ & $3.8 / 1.6$ & $2.3 / 1.1$ & $0.5 / 0.2$ & $0.4 / 0.1$ & $0.4 / 0.07$ \\
$\begin{array}{c}\alpha-\text { Fetoprotein } \\
(8.5 \pm 5.5 \mathrm{ng} / \mathrm{ml})\end{array}$ & 41420 & 17270 & 892 & 101 & 2.6 & 2.2 \\
$\begin{array}{c}\text { ALT }(12-45 \mathrm{IU} / \mathrm{L}) / \\
\text { AST }(22-63 \mathrm{IU} / \mathrm{L})\end{array}$ & $125 / 171$ & $96 / 103$ & $53 / 72$ & $45 / 58$ & $24 / 62$ & $22 / 51$ \\
$\begin{array}{c}\text { Citrulline } \\
(6-35 \mu \mathrm{mol} / \mathrm{L})\end{array}$ & 255 & 15.9 & 13 & 9 & - & 22 \\
$\begin{array}{c}\text { Threonine } \\
(33-160 \mu \mathrm{mol} / \mathrm{L})\end{array}$ & 363 & 653 & 143 & 49 & - & 59 \\
$\begin{array}{l}\text { Threonine/Serine }(1.1) \\
\text { Galactosuria }\end{array}$ & 3.36 & 8.8 & 2.0 & 1.4 & - & 1.2 \\
\hline
\end{tabular}


acid levels were normal. Based on these metabolic abnormalities, neonatal intrahepatic cholestatic hepatitis caused by citrin deficiency was strongly suspected. Mutation analysis of SLC25A13 gene confirmed the diagnosis. A missense NM_014251.2:c.1354G > A(dbSNP: rs143877538) causes a protein 68 defect; NP_055066.1:p.Val452Ile (homozygous) mutation was detected by next generation sequencing, Miseq, Illumina (Illumina, San Diego, CA, USA) (Fig. 1), the minor allele frequency of this variant was given as nearly 0.01 in South Asian population. As this frequency supports the possibility of being a polymorphism, some in silico evaluations predict it as a disease causing variant (Mutation Taster prob: 0.999999993576759, Polyphen2 score: 1), while SIFT predicts it as a tolerated variant (SIFT score: 0.13). The child was treated with formulas containing mediumchain triglycerides, ursodeoxycholic acid and fat-soluble vitamin supplementation due to his clinical features strongly supports the diagnosis. As shown in Table I, we observed the progressive normalization of liver function tests, aminoacid levels and recovery of galactosuria. In the 18 month follow-up the patient no longer presented with jaundice and showed normal mental development and weight-height gain. Bilirubin, citrulline and alpha-fetoprotein levels remained in the normal range.

The study was reviewed and approved by an instutional review board. Written informed consent were provided by both of the parents.

\section{Discussion}

Although NICCD is mostly a benign condition, some of the cases could develop chronic liver failure and need liver transplantation to survive ${ }^{4}$. Major presentations of NICCD are cholestatic jaundice, and hepatomegaly. Coagulopathy, hypoglycemia and hypoalbuminemia could be the other presenting features. Splenomegaly has been rarely reported as an initial presenting finding ${ }^{3}$. Elevated citrulline levels, alfa fetoprotein levels and AST/ALT ratio are the other important markers of the disease ${ }^{5}$. Plasma aminoacids analysis showed moderately elevated plasma citrulline and threonine and mildly elevated tyrosine (Table I). High citrulline, alpha-fetoprotein level and AST/ALT ratio were significant in our patient.
Galactosemia is often previously considered rather than NICCD and these patients may be treated incidentally for galactosemia with lactose-free formula ${ }^{6}$. Markedly elevated levels of citrulline and alpha-fetoprotein are determinative. Tyrosinemia and mitochondrial DNA depletion syndrome are the other inherited metabolic diseases that should be considered in the differential diagnosis of $\mathrm{NICCD}^{2}$. Due to the findings of galactosuria and cholestasis, galactosemia was one of the major causes of the differential diagnosis. With the absence of the cataract and normal activity of the galactose-1-phosphate uridyl transferase enzyme, we ruled out the diagnosis of galactosemia. Similarly, normal levels of tyrosine and absence of succinylacetone in the urine organic acid analysis excluded the diagnosis of tyrosinemia.

Although the NP_055066.1:p.Val452Ile variant is not clear a mutation due to its high frequency in South Asia and in silico evaluation results, clinical picture of our patient most probably supports its disease causing nature. ${ }^{7}$ It is firstly reported in the Turkish and European populations. Our team has the data of 512 exome analysis and this variant was not detected in that population. This variant is it the conserved area of the gene and protein in different species like M. mulatta, F. catus, $M$. musculus, G. gallus, D. melanogaster, C. elegans and $X$. tropicalis. It is considered to be a diseasecausing variant ${ }^{7}$.

NICCD is not a self-limiting condition; progressive liver failure or adult-onset type II citrullinemia (CTLN2) may develop ${ }^{8}$. NICCD should be considered in the cases of neonatal cholestasis, especially in differential diagnosis of galactosemia due to galactosuria and tyrosinemia due to elevated levels of alphafeto-protein. Also dietary treatment should be applied early, as a dramatic response is to be expected.

\section{REFERENCES}

1. Wang JS, Wang XH, Zheng YJ, et al. Biochemical characteristics of neonatal cholestasis induced by citrin deficiency. World J Gastroenterol 2012; 21: 5601-5607.

2. Kobayashi K, Saheki T, Song YZ. Citrin Deficiency. 2005 [Updated 2014 Jul 31]. In: Pagon RA, Adam MP, Ardinger $\mathrm{HH}$, et al. GeneReviews ${ }^{\circledR}$ [Internet]. Seattle (WA): University of Washington, Seattle. 
3. Treepongkaruna S, Jitraruch S, Kodcharin P, et al. Neonatal intrahepatic cholestasis caused by citrin deficiency: prevalence and SLC25A13 mutations among Thai infants. BMC Gastroenterol 2012; 15: 141.

4. Shigeta T, Kasahara M, Kimura T, et al. Liver transplantation for an infant with neonatal intrahepatic cholestasis caused by citrin deficiency using heterozygote living donor. Pediatr Transplant 2010; 14: 86-88.

5. Song YZ, Li BX, Chen FP, et al. Neonatal intrahepatic cholestasis caused by citrin deficiency: clinical and laboratory investigation of 13 subjects in mainland of China. Dig Liver Dis 2009; 41: 683-689.
6. Thong MK, Boey CC, Sheng JS, Ushikai M, Kobayashi K. Neonatal intrahepatic cholestasis caused by citrin deficiency in two Malaysian siblings: outcome at one year of life. Singapore Med J 2010; 51: 12-14.

7. Cunningham F, Amode MR, Barrell D, et al. Ensembl 2015. Nucleic Acids Res 2015; 43: 662-669.

8. Chew HB, Ngu LH, Zabedah MY, et al. Neonatal intrahepatic cholestasis associated with citrin deficiency (NICCD): a case series of 11 Malaysian patients. J Inherit Metab Dis 2010; 33: 489-495. 